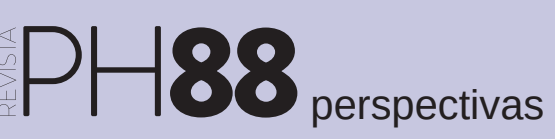

a debate La eficiencia energética y la edificación histórica | coordinan Mónica López Sánchez, Ana Yáñez Vega

\title{
La intervención energética en el patrimonio edificado: un problema no resuelto
}

Eneko Jokin Uranga Santamaria, Lauren Etxepare Igiñiz | Dpto. de Arquitectura Escuela Técnica Superior de Arquitectura de San Sebastián, U. del País Vasco

URL de la contribución <www.iaph.es/revistaph/index.php/revistaph/article/view/3657>

Uno de los problemas más importantes a nivel mundial de nuestro tiempo es el problema energético y la incidencia de éste en el medio ambiente. Entre todas las comunidades internacionales ha sido la UE la que ha tomado la iniciativa para intentar solucionar este problema, y el sector de la construcción ha sido el primero en ser señalado como corresponsable de gran cantidad de emisiones de GEI y de un excesivo gasto energético. En este sentido hay que tener en cuenta dos realidades. Por un lado, es que la mayoría del consumo energético que se hace en este sector de la construcción lo realizan los edificios existentes. La otra es que una gran parte de estos edificios son inmuebles que forman parte del patrimonio edificado o tienen algún grado de protección. Aún no se ha dado una posible solución al problema que se plantea, y es que en un principio la intervención energética y la conservación del patrimonio parten de realidades opuestas.

\section{El patrimonio edificado y la intervención energética}

Ya llevamos un tiempo en el que las diferentes instituciones tanto públicas como privadas están en marcha para buscar soluciones al problema energético en la construcción. Pero también es verdad que, en la mayor parte de los casos, se ha profundizado en la búsqueda de soluciones de mejora energética de los materiales y de los sistemas, y no tanto en la consecuencia de la aplicación de estas soluciones sobre la arquitectura. Si tenemos en cuenta que todas estas soluciones planteadas se deben aplicar a través de intervenciones energéticas en el parque edificado existente, aún no sabemos, de manera global, las consecuencias que tendrán éstas en la imagen y configuración original de los edificios. Si estos edificios además forman parte del patrimonio edificado se complica la resolución del problema. Si se interviene sin tener en cuenta los valores arquitectónicos, perderemos valores culturales irrecuperables. En cambio, si no actuamos, perderemos la oportunidad de mejorar estos edificios, y por supuesto lograr los objetivos energéticos establecidos.

\section{La consideración de patrimonio edificado de nuestras ciudades}

Un punto conflictivo de esta dicotomía es qué se considera patrimonio edificado y qué no. Los grandes edificios monumentales que están protegidos por sus valores histórico-artísticos quedan fuera de este debate, ya que están debidamente protegidos dentro de una legislación a nivel estatal y autonómico creada a tal efecto. Pero ¿qué sucede con los edificios que disponen de algún grado menor de protección, o incluso ninguno, pero que son los que configuran los entornos y paisajes urbanos de nuestras ciudades? A nivel internacional cada vez se tiene más en cuenta este tipo de edificios y en muchos casos son considerados parte del patrimonio edificado. En este sentido desde hace unas décadas se está desarrollando una sensibilidad especial en la profundización de la consideración de patrimonio y como consecuencia de ello se está ampliando el sentido del mismo. La consideración de patrimonio edificado, al menos a nivel europeo, va en aumento cuantitativamente y cualitativamente. Por ello cada vez es más fundamental la conservación del carácter y presencia de nuestras ciudades y de los edificios que las configuran a pesar de no tener en la actualidad ningún tipo de protección.

\section{La legislación frente a la intervención energética del patrimonio edificado}

La legislación actual, tanto la europea como la española, no se ha pronunciado frente a esta problemática. Deja 
al margen de la intervención energética a todo edificio que tenga algún grado de protección, pudiendo ser éste desde un Bien de Interés Cultural a nivel nacional, o un simple elemento constructivo protegido a nivel local. En la actualidad no disponemos más que de dos planteamientos: o se interviene libremente al margen del deterioro que puede sufrir el inmueble buscando un resultado únicamente energético, o si pretendemos proteger el inmueble de alguna manera no se interviene en él desde un punto de vista energético. Parece que ninguna de las dos opciones da respuesta a las necesidades que se plantean en la actualidad, y tampoco tiene en cuenta la importancia del grado de protección que tiene cada edificio.

\section{¿Tiene solución el problema?}

Por todo ello, y ante esta falta de solución intermedia, se propone desde este foro justamente eso, la intervención intermedia. O dicho de otra manera: la intervención energética que se adecue al edificio en el que se va a actuar y se adapte al grado de protección y al nivel de importancia que tenga. En ningún caso será lo mismo actuar en el Alcázar de Segovia que en un inmueble residencial que forma parte del Ensanche Cortázar de San Sebastián.
Cada uno tiene un grado de valor histórico, artístico y arquitectónico, y aunque ambos tienen la posibilidad de que sean intervenidos desde un punto de vista energético, las soluciones y objetivos que se deberían plantear para cada uno de ellos no podrán ser los mismos.

\section{Propuesta a debate}

Por ello, desde este foro y para ser llevado a debate, se plantea la posibilidad de "clasificar" doblemente los edificios, en función de su importancia patrimonial y de la intervención energética que pueda acometerse. Es decir, cada edificio tiene un grado de intervención energética en base al nivel de protección que tenga. No podemos buscar para todos los edificios un mismo objetivo energético, ni desechar la posibilidad de intervenir en ellos por el mero hecho de estar protegidos. De esta manera la intervención energética será gradual, lo mismo que la protección de los edificios, y se puede llegar a "clasificar en grados" según la realidad de cada uno de ellos. Sólo faltaría determinar los posibles objetivos energéticos que se podrían alcanzar y clasificar la cantidad de edificios objeto de protección de que disponemos en nuestras ciudades, pueblos y entornos.

Nivel de Conservación del Patrimonio Edificado
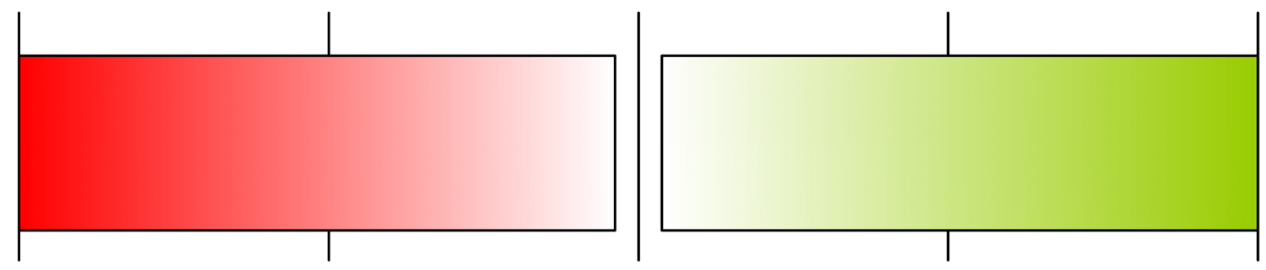

Nivel de Eficiencia Energética

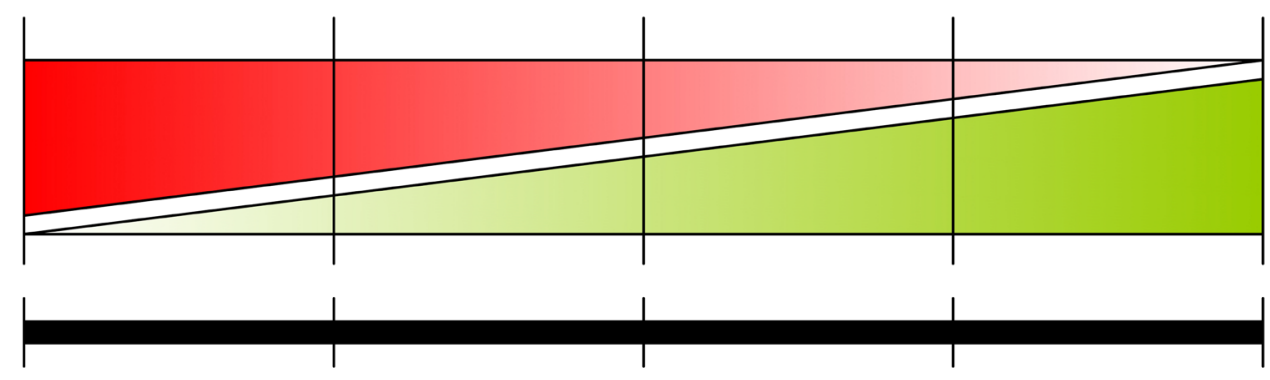

Nivel de Eficiencia

Nivel de Conservación del Patrimonio Edificado

Energética

Tal y como plantea la legislación actual, la interrelación entre el nivel de conservación del patrimonio edificado y el nivel de intervención energética no es posible (gráfico superior). Para que esta interrelación sea posible, se debería tener en cuenta tanto el grado de protección del edificio como el objetivo energético a lograr. Dividiéndolo en grados, se plantea que cuanto mayor nivel de protección tenga el edificio, menor nivel de logro energético pudiera obtenerse, y viceversa (gráfico inferior) | gráficos Eneko J. Uranga 
a debate La eficiencia energética y la edificación histórica | coordinan Mónica López Sánchez, Ana Yáñez Vega

\section{BIBLIOGRAFÍA}

- AZKarate, A.; RUIZ DE AEL, M. J.; SANTANA, A. (2003) El patrimonio Arquitectónico. Ponencia presentada al Plan Vasco de Cultura. Vitoria-Gasteiz: Servicio Central de Publicaciones del Gobierno Vasco, 2004

- CAPITEL, A. (1983) El tapiz de Penélope. Arquitectura, n. ${ }^{\circ}$ 244, 1983

- CAPITEL, A. (2011) Notas sobre la identidad y la protección de los bienes patrimoniales modernos. Ponencia "Criterios de intervención en el patrimonio arquitectónico del siglo XX". En Conferencia Internacional CAH20thC. Madrid: Ministerio Cultura, 2011, pp. 79-84

- CHOAY, F. (2007) Alegoría del patrimonio. Barcelona: Gustavo Gili, 2007

- DIRECTIVA 2012/27/UE del Parlamento y del Consejo, de 25 de octubre de 2012, relativa a la eficiencia energética, por la que se modifican las Directivas 2009/125/CE y 2010/30/UE, y por la que se derogan las Directivas 2004/8/CE y 2006/32/CE. DOUE, n. ${ }^{\circ} 315$, de 14 de noviembre de 2012

- DIRECTIVA 2010/31/UE del Parlamento Europeo y del Consejo, de 19 de mayo de 2010, relativa a la eficiencia energética de los edificios (refundición). DOUE, n. ${ }^{\circ} 153$, de 18 de junio de 2010

- LEY 16/1985, de 25 de junio, del Patrimonio Histórico Español. Boletín Oficial Estado, n. ${ }^{\circ} 155$, de 29 de junio de 1985

- LEY 7/1990, de 3 de julio, de Patrimonio Cultural Vasco. Boletín Oficial País Vasco, n. ${ }^{\circ}$ 157, de 6 de agosto de 1990
- LEY 8/2013 sobre la Rehabilitación, Regeneración y Renovación Urbanas. Boletín Oficial Estado, n. ${ }^{\circ}$ 153, de 27 de junio de 2013

- ORDEN FOM/1635/2013, de 10 de septiembre, por la que se actualiza el documento Básico DB-HE "Ahorro de Energía", del Código técnico de la edificación, aprobado por Real Decreto 314/2006, de 17 de marzo. Boletín Oficial Estado, n. ${ }^{\circ} 219$, de 12 de septiembre de 2013

- REAL DECRETO 235/2013, de 13 de abril de 2013, por el que se aprueba el procedimiento básico para la certificación de la eficiencia energética de los edificios. Boletín Oficial Estado, n. ${ }^{\circ} 89$, de 13 de abril de 2013

- SOLÁ-MORALES, I. (1982) Teorías de intervención arquitectónica. Quaderns d'arquitectura i urbanismo, n. ${ }^{\circ} 155$ 1982

- URANGA, E. J.; ETXEPARE, L. (2014) Beneficios y riesgos de la rehabilitación energética en el patrimonio edificado: 5 grados de protección. En Congreso Internacional de Eficiencia Energética y Edificación Histórica. Madrid: Fundación de Casas Históricas y Singulares, Fundación Ars Civilis, 2014, pp. 464-477

- URANGA, E. J.; ETXEPARE, L.; LIZUNDIA, I.; SAGARNA, M. (2014) Beneficios y riesgos de la rehabilitación energética en el patrimonio edificado: 5 grados de protección. En 5th European Conference on Energy Efficiency and Sustainability in Architecture and Planning - EESAP. Donostia-San Sebastián: Universidad del País Vasco/Euskal Herriko Unibertsitatea, 2014, pp. 203-210 